\title{
Sociodemographic risk factors associated with metabolic syndrome in a Mediterranean population
}

\author{
Genevieve Buckland ${ }^{1}$, Jordi Salas-Salvadó ${ }^{2,3, *}$, Eulàlia Roure ${ }^{4}$, Mònica Bulló ${ }^{2}$ and \\ Lluís Serra-Majem ${ }^{5}$ \\ 'Unit of Nutrition, Environment and Cancer, Epidemiological Research Programme, Catalan Institute of \\ Oncology-IDIBELL, Barcelona, Spain: ${ }^{2}$ Unitat de Nutrició Humana, Hospital Universitari de Sant Joan, \\ Departament de Bioquímica i Biotecnologia, Facultat de Medicina i Ciències de la Salut, Universitat Rovira i \\ Virgili, C/Sant Llorenç 21, E-43201 Reus, Spain: ${ }^{3}$ CIBER Fisiopatologia de la Obesidad y Nutrición (CB06/03), \\ Instituto Salud Carlos III, Madrid, Spain: ${ }^{4}$ Public Health Division, Department of Health, Autonomous Government \\ of Catalonia, Barcelona, Spain: ${ }^{5}$ Department of Clinical Sciences, University of Las Palmas de Gran Canaria, \\ Las Palmas de Gran Canaria, Spain
}

Submitted 24 January 2008: Accepted 7 July 2008: First published online 15 August 2008

\begin{abstract}
Objective: To investigate the sociodemographic risk factors associated with metabolic syndrome (MetS) in the Mediterranean population of Catalonia, Spain. Design and setting: Data from the cross-sectional, population-based 2002-2003 Health Survey of Catalonia were analysed. The survey used a structured questionnaire to collect information on demographics, lifestyle and medical history. In a sub-sample of the original survey population anthropometrics and blood pressure were measured and blood samples were taken to determine HDL cholesterol, TAG and fasting glucose.

Subjects: The analysis included the 1104 individuals aged 18-74 years from this sub-sample who had complete information on all variables necessary to define MetS using the National Cholesterol Education Program's Adult Treatment Panel III (ATP III) and the International Diabetes Federation (IDF) criteria.

Results: MetS prevalence was $28 \cdot 5 \%$ and $24 \cdot 8 \%$ according to IDF and ATP III criteria, respectively. MetS was significantly $(P=0.05)$ more common in males than females. MetS prevalence increased significantly $(P<0 \cdot 001)$ with age and degree of adiposity and as social class decreased. In general, MetS prevalence decreased as physical activity increased, which was significant $(P=0 \cdot 0253)$ when applying ATP III criteria. After taking into account important confounders, MetS prevalence was significantly positively associated with male gender, age, BMI, physical inactivity and lower social class. Smoking status, marital status and working situation were not independently associated with MetS.

Conclusions: Age, sex, degree of adiposity, physical activity and social class are the sociodemographic risk factors independently associated with MetS in this Mediterranean population. Understanding which factors predict MetS is important considering likely increasing MetS trends, and is useful for determining public health strategies.
\end{abstract}

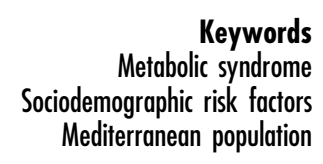

The term metabolic syndrome (MetS) describes a clustering of risk factors for CVD. MetS is characterised by the presence of insulin resistance, atherosclerotic dyslipidaemia, hypertension and abdominal obesity ${ }^{(1,2)}$, and is associated with an increased risk of atherosclerotic disease and a greater incidence of cardiovascular events, type 2 diabetes and total mortality ${ }^{(3,4)}$. In developed countries MetS is a common condition, prevalent in about $25 \%$ of the population ${ }^{(5-7)}$, although it has been reported to be almost as high in certain developing countries as well ${ }^{(8,9)}$. There is some evidence that MetS has become more prevalent over the last decade ${ }^{(5,10,11)}$, probably influenced in part by increases in obesity, and this will worsen the public health burden of MetS-related morbidity and mortality.

The aetiology of MetS, although not entirely understood, is considered to reside in a complex interaction between genetic, metabolic and environmental factors ${ }^{(12,13)}$. Understanding what factors are predictive of MetS and how these risk factors are distributed and interrelated within different populations is important for identifying and targeting populations at risk, thus helping in the development and implementation of public health interventions. Previous epidemiological studies in American, 
Asian and European populations have documented an increased prevalence of MetS in men, older age groups, overweight/obese and physically inactive individuals, lower social classes, smokers and certain ethnic groups ${ }^{(10,14-17)}$. However, because Mediterranean populations have low CVD mortality and increased total longevity ${ }^{(18-20)}$, it is also of interest to analyse if the predictive risk factors of MetS in these populations remain the same.

There is considerable evidence that the traditional Mediterranean dietary pattern (MDP) is one of the lifestyle traits protective against many of the cardiovascular risk factors used to define MetS, including improvements in insulin resistance, lipid profile, hypertensive status and degree of adiposity or abdominal obesity ${ }^{(21-26)}$. Along with these benefits, adherence to a traditional MDP has also been associated with improvements in endothelial dysfunction, oxidation and vascular inflammation ${ }^{(24,27,28)}$, thereby modifying the risk of MetS ${ }^{(29,30)}$. In fact, the MDP has been reported to be inversely associated with overall MetS prevalence ${ }^{(31)}$ and incidence ${ }^{(23)}$ in Mediterranean populations.

To the best of our knowledge, no study to date has explored how sociodemographic risk factors of MetS are distributed and interrelated in a representative sample of a specifically Mediterranean population, whose dietary pattern is protective against MetS. Therefore, the aim of the present study was to examine the sociodemographic risk factors of MetS in a Mediterranean population (Catalonia, Spain), defining MetS using the National Cholesterol Education Program's Adult Treatment Panel III (ATP III) and the International Diabetes Federation (IDF) criteria.

\section{Participants and methods}

The study involved an analysis of cross-sectional data from the Health Survey of Catalonia in 2002-2003. This survey was carried out on a random sample of the population of Catalonia and included a representative sample of civilian non-institutionalised adults. The Ethical Committee of the Department of Health of the Catalan Government approved the survey, and all participants gave fully informed written consent.

The survey methodology has been detailed elsewhere ${ }^{(32)}$ and summarised in our previous study, which used the same data to investigate MetS trends in the last 10 years ${ }^{(11)}$. In brief, after the initial survey, participants (aged 18-75 years) were invited to undergo an additional clinical examination. The sex and age of the individuals who accepted were comparable to the individuals from the initial samples ${ }^{(32,33)}$. A structured survey was used to collect information on each individual's sociodemographic characteristics, medical history and other health markers. The clinical health examination involved a physical examination, anthropometric and blood pressure measurements, and biochemical analysis in blood and urine samples.
MetS was defined by both ATP III and IDF definitions $^{(1,34)}$. ATP III defines an individual as having MetS if three or more of the following five diagnostic criteria are present: (i) waist circumference $\geq 102 \mathrm{~cm}$ in men and $\geq 88 \mathrm{~cm}$ in women; (ii) hypertriacylglycerolaemia, TAG $\geq 150 \mathrm{mg} / \mathrm{dl}(1.695 \mathrm{mmol} / \mathrm{l})$ or use of antihypertriacylglycerolaemic medication; (iii) low HDL-cholesterol (HDL-C), HDL-C $<40 \mathrm{mg} / \mathrm{dl}(0.9 \mathrm{mmol} / \mathrm{l})$ in men and $<50 \mathrm{mg} / \mathrm{dl}(1 \cdot 1 \mathrm{mmol} / \mathrm{l})$ in women or use of medication to reduce cholesterol; (iv) hypertension, blood pressure $\geq 130 / 85 \mathrm{mmHg}$ or use of antihypertensive medication; and (v) hyperglycaemia, fasting glucose $\geq 100 \mathrm{mg} / \mathrm{dl}$ $(\geq 6 \cdot 1 \mathrm{mmol} / \mathrm{l})$ or use of antihyperglycaemic medication. The IDF definition is similar but the abdominal obesity cut-off values are lower $(\geq 94 \mathrm{~cm}$ for European men and $\geq 80 \mathrm{~cm}$ for European women), abdominal obesity is a conditional component of the MetS and individuals are also classed as hyperglycaemic if they have previously been diagnosed with type 2 diabetes. Information available on diabetes, medication for hypertension, low HDL-C and hyperglycaemia was self-reported. Medication use for hypertriacylglycerolaemia was not included in the definition, as information was not collected for this variable. Data from 1104 individuals were available for the analysis, after excluding individuals from the sub-sample with incomplete information on metabolic abnormalities used to define MetS.

The STATA statistical software package version 9.1 (Stata Corp, College Station, TX, USA) was used to analyse MetS prevalence according to sociodemographic characteristics (age, sex, marital status, working situation and social class) and potentially modifiable lifestyle characteristics (BMI, physical activity level and smoking status). BMI was categorised using standard cut-offs ${ }^{(35)}$. The odds ratios of MetS according to the characteristics studied were calculated using multiple logistic regression analyses. The two lowest age groups (18-24 and 25-34 years) were combined and used as the reference subgroup, as no significant difference in odds was seen between them in the single-factor logistic regression analysis. Interactions between the risk factors were explored by applying the likelihood ratio test.

\section{Results}

A total of 1104 individuals were included in the analysis sample, ranging from 18 to 74 years old (mean 44.9 (sD 15.1) years), of whom $56 \cdot 1 \%$ ( $n$ 619) were women. The general characteristics of the sample are presented in Table 1 . The global prevalence of MetS according to IDF criteria was $28.5 \%$ (95\% CI $25 \cdot 9,31 \cdot 2 \%$ ), and according to ATP III criteria was $24 \cdot 8 \%(95 \%$ CI $22 \cdot 3,27 \cdot 4 \%)$. Table 2 shows the results of the single-factor logistic regression analysis for the prevalence of MetS according to sociodemographic characteristics, applying ATP III and IDF criteria. 
Table 1 Characteristics of the study population: sub-sample of individuals aged 18-74 years from the 2002-2003 Health Survey of Catalonia

\begin{tabular}{|c|c|c|c|c|c|c|}
\hline \multirow[b]{2}{*}{ Baseline characteristic } & \multicolumn{2}{|c|}{$\begin{array}{l}\text { Women } \\
(n \text { 619) }\end{array}$} & \multicolumn{2}{|c|}{$\begin{array}{c}\text { Men } \\
(n \text { 485) }\end{array}$} & \multicolumn{2}{|c|}{$\begin{array}{l}\text { Total population } \\
\quad(n 1104)\end{array}$} \\
\hline & Mean or $n$ & SD or $\%$ & Mean or $n$ & SD or $\%$ & Mean or $n$ & SD or $\%$ \\
\hline Age (years) & $44 \cdot 2$ & $15 \cdot 2$ & $45 \cdot 9$ & $14 \cdot 8$ & $44 \cdot 9$ & $15 \cdot 1$ \\
\hline Current smokers & 166 & $27 \cdot 0$ & 182 & $38 \cdot 2$ & 348 & 31.9 \\
\hline $\mathrm{BMI}\left(\mathrm{kg} / \mathrm{m}^{2}\right)$ & $25 \cdot 9$ & 4.9 & $26 \cdot 8$ & 3.9 & $26 \cdot 3$ & 4.5 \\
\hline $\mathrm{BMI} \geq 25 \mathrm{~kg} / \mathrm{m}^{2}$ & 312 & $51 \cdot 8$ & 318 & $67 \cdot 0$ & 630 & $58 \cdot 5$ \\
\hline $\mathrm{BMI} \geq 30 \mathrm{~kg} / \mathrm{m}^{2}$ & 122 & $20 \cdot 3$ & 87 & $18 \cdot 3$ & 209 & $19 \cdot 4$ \\
\hline Waist circumference $(\mathrm{cm})$ & $82 \cdot 3$ & $12 \cdot 7$ & $92 \cdot 7$ & $11 \cdot 0$ & 86.9 & $13 \cdot 1$ \\
\hline Diabetic & 30 & 4.9 & 37 & $7 \cdot 6$ & 67 & $6 \cdot 1$ \\
\hline Medication for diabetes & 19 & $3 \cdot 1$ & 26 & $5 \cdot 4$ & 45 & $4 \cdot 1$ \\
\hline Hypertensive $^{\star}$ & 245 & $39 \cdot 6$ & 245 & $50 \cdot 5$ & 490 & $44 \cdot 3$ \\
\hline Medication for hypertension & 59 & $9 \cdot 6$ & 64 & $13 \cdot 2$ & 123 & $11 \cdot 2$ \\
\hline Hypertriacylglycerolaemia* & 52 & $8 \cdot 4$ & 99 & $20 \cdot \overline{4}$ & 152 & $13 \cdot \overline{7}$ \\
\hline Low HDL cholesterol* & 210 & 33.9 & 171 & $35 \cdot 3$ & 381 & $34 \cdot 5$ \\
\hline Medication for hypercholesterolaemia & 40 & $6 \cdot 5$ & 29 & $6 \cdot 0$ & 69 & $6 \cdot 3$ \\
\hline MetS, ATP III criteria & 140 & $22 \cdot 6$ & 134 & $27 \cdot 6$ & 274 & $24 \cdot 8$ \\
\hline MetS, IDF criteria & 162 & $26 \cdot 2$ & 153 & $31 \cdot 6$ & 315 & 28.5 \\
\hline
\end{tabular}

MetS, metabolic syndrome; ATP III, National Cholesterol Education Program Adult Treatment Panel III; IDF, International Diabetes Foundation.

*Defined using cut-offs within ATP III and IDF definitions/includes individuals taking medication for this medical condition.

Table 3 presents the results of the multiple logistic regression models, giving the likelihood of having MetS (for both definitions) for age, sex, BMI, physical activity and social class. Working situation, marital status and smoking did not enter the final model as they were not found to be independently associated with MetS; the likelihood ratio test of the difference between models including and excluding these variables separately was not significant, indicating they were not major confounders.

MetS was more prevalent in older compared with younger age groups (Table 2 ). Only $2 \cdot 5 \%$ of individuals aged 18-24 years had MetS (both criteria), whereas 59.7\% (IDF criteria) and $51 \cdot 1 \%$ (ATP III criteria) of 65-74-yearolds had MetS, with a significant trend $(P<0 \cdot 001)$ for an increase in MetS with age. In addition, the presence of four or all five of the MetS criteria increased with age (results not shown). In the multiple variable logistic regression analysis (Table 3), age was independently associated with risk of having MetS after controlling for important confounders; 65-74-year-olds were 12.9 times (IDF criteria) or $11 \cdot 1$ times (ATP III criteria) more likely to have MetS compared with 18-34-year-olds ( $P$ for trend $<0 \cdot 001)$.

MetS was significantly less common in females than in males, using both MetS definitions (Table 2); applying IDF criteria $31.6 \%$ of males had MetS compared with $26 \cdot 2 \%$ of females $(P=0 \cdot 050)$. This gender effect remained after adjusting for important confounders (Table 3). When applying ATP III criteria females were $40 \%(P=0 \cdot 010)$ less likely to have MetS than males. However, when applying IDF criteria, although females were $30 \%$ less likely to have MetS than males, this did not reach a level of statistical significance $(P=0 \cdot 084)$.

As expected, the prevalence of MetS increased $(P<0 \cdot 001)$ with BMI in the single factor analysis applying both definitions (Table 2). Over $60 \%$ of obese individuals had MetS, compared with about $5 \%$ of normal-weight individuals. In addition, the presence of four or all five of the MetS criteria increased with BMI and almost no normal-weight individuals had more than three MetS components (results not shown). BMI was also independently associated with the risk of having MetS after controlling for important confounders (Table 3 ). Obese individuals were $22 \cdot 0$ times (IDF criteria) and $16 \cdot 4$ times (ATP III criteria) more likely to have MetS than normal-weight individuals ( $P$ for trend $<0.001$ ).

MetS prevalence tended to decrease when physical activity increased in the single factor analysis (Table 2). After adjusting for important confounders, the effect of exercise only became apparent in the active group, who had a $50 \%$ lower risk of having MetS than the inactive group (Table 3). However, the trend of decreasing MetS risk with increasing physical activity was significant only when applying ATP III criteria $(P$ for trend $=0 \cdot 054)$.

MetS was most prevalent in individuals from lower social classes and decreased gradually as social class increased $(P<0 \cdot 001)$. Over $30 \%$ of individuals from low social class had MetS, while MetS was present in $16 \cdot 8 \%$ (ATP III criteria) and $19 \cdot 6 \%$ (IDF criteria) of individuals from high social class (Table 2). Social class was also independently associated with risk of MetS (Table 3), but the effect reached significance only in the low social class group, who were $2 \cdot 0$ (95\% CI $1 \cdot 1,3 \cdot 7)$ and 1.9 (95\% CI $1 \cdot 1,3 \cdot 5)$ times more likely to have MetS than the high social class group, when applying ATP III and IDF criteria respectively.

Applying both ATP III and IDF criteria, MetS was most prevalent in past smokers (Table 2). In relation to marital and working status, MetS was most common in individuals who were married/living together and in retired individuals. 
Table 2 The prevalence of MetS according to sociodemographic characteristics, applying ATP III and IDF criteria: sub-sample of individuals aged 18-74 years from the 2002-2003 Health Survey of Catalonia

\begin{tabular}{|c|c|c|c|c|c|c|c|c|}
\hline \multirow[b]{2}{*}{ Variable } & \multicolumn{2}{|c|}{ Subjects } & \multicolumn{3}{|c|}{ MetS, ATP III criteria } & \multicolumn{3}{|c|}{ MetS, IDF criteria } \\
\hline & $n$ & $\%$ & $\geq 3(\%)^{\star}$ & $95 \% \mathrm{Cl}$ & $P$ for trend & $\geq 3(\%)^{*}$ & $95 \% \mathrm{Cl}$ & $P$ for trend \\
\hline Total & 1104 & 100 & $24 \cdot 8$ & $22 \cdot 3,27 \cdot 4$ & $\mathrm{~N} / \mathrm{A}$ & $28 \cdot 5$ & $25 \cdot 9,31 \cdot 2$ & $\mathrm{~N} / \mathrm{A}$ \\
\hline Sex & 1104 & & & & & & & \\
\hline Women & 619 & $56 \cdot 1$ & $22 \cdot 6$ & $19 \cdot 3,25 \cdot 9$ & 0.056 & $26 \cdot 2$ & $22 \cdot 7,29 \cdot 6$ & 0.050 \\
\hline Men & 485 & $43 \cdot 9$ & $27 \cdot 6$ & $23 \cdot 6,31 \cdot 6$ & & $31 \cdot \overline{6}$ & $27 \cdot 4,35 \cdot 7$ & \\
\hline Age (years) & 1104 & & & & & & & \\
\hline $18-24$ & 118 & $10 \cdot 7$ & $2 \cdot 5$ & $0 \cdot 3,5 \cdot 4$ & $<0.001$ & $2 \cdot 5$ & $0 \cdot 3,5 \cdot 4$ & $<0.001$ \\
\hline $25-34$ & 190 & $17 \cdot 2$ & $7 \cdot 4$ & $3 \cdot 6,11 \cdot 1$ & & $9 \cdot 0$ & $4 \cdot 9,13 \cdot 0$ & \\
\hline $35-44$ & 238 & $21 \cdot 6$ & $14 \cdot 7$ & $10 \cdot 2,19 \cdot 2$ & & $19 \cdot 8$ & $14 \cdot 7,24 \cdot 8$ & \\
\hline $45-54$ & 235 & $21 \cdot 3$ & $29 \cdot 8$ & $23 \cdot 9,35.7$ & & $32 \cdot 3$ & $26 \cdot 3,38 \cdot 4$ & \\
\hline $55-64$ & 184 & $16 \cdot 7$ & $44 \cdot 0$ & $36 \cdot 8,51 \cdot 3$ & & $48 \cdot 4$ & $41 \cdot 1,55 \cdot 7$ & \\
\hline $65-74$ & 139 & $12 \cdot 6$ & $51 \cdot 1$ & $42 \cdot 7,59 \cdot 5$ & & $59 \cdot 7$ & $51 \cdot 5,68 \cdot 0$ & \\
\hline Marital status & 1100 & & & & & & & \\
\hline Married/couple & 795 & $72 \cdot 3$ & $29 \cdot 7$ & $26 \cdot 5,32 \cdot 9$ & $\mathrm{~N} / \mathrm{A}$ & $33 \cdot 5$ & $30 \cdot 2,36 \cdot 7$ & $\mathrm{~N} / \mathrm{A}$ \\
\hline Single & 238 & $21 \cdot 6$ & $8 \cdot 0$ & $4 \cdot 5,11 \cdot 5$ & & $11 \cdot 3$ & $7 \cdot 3,15 \cdot 4$ & \\
\hline Othert & 67 & $6 \cdot 1$ & $28 \cdot 4$ & $17 \cdot 3,39 \cdot 4$ & & $29 \cdot 9$ & $18 \cdot 6,41 \cdot 1$ & \\
\hline Working situation & 1103 & & & & & & & \\
\hline Working & 616 & $55 \cdot 9$ & $19 \cdot 3$ & $16 \cdot 2,22 \cdot 4$ & N/A & $22 \cdot 9$ & $19 \cdot 6,26 \cdot 2$ & $\mathrm{~N} / \mathrm{A}$ \\
\hline Housewife/husband & 190 & $17 \cdot 2$ & $34 \cdot 7$ & $27 \cdot 9,41 \cdot 6$ & & $37 \cdot 4$ & $30 \cdot 4,44 \cdot 3$ & \\
\hline Unemployed & 81 & $7 \cdot 3$ & $19 \cdot 8$ & $10 \cdot 9,28 \cdot 6$ & & $19 \cdot 8$ & $10 \cdot 9,28 \cdot 6$ & \\
\hline Retired & 156 & $14 \cdot 1$ & $44 \cdot 9$ & $37 \cdot 0,52 \cdot 8$ & & $51 \cdot 9$ & $44 \cdot 0,59 \cdot 9$ & \\
\hline Other & 60 & $5 \cdot 4$ & $5 \cdot 0$ & $0 \cdot 6,10 \cdot 7$ & & $8 \cdot 3$ & $1 \cdot 1,15 \cdot 5$ & \\
\hline Social class & 1068 & & & & & & & \\
\hline Low & 202 & $18 \cdot 9$ & $31 \cdot 7$ & $25 \cdot 2,38 \cdot 1$ & $<0.001$ & $35 \cdot 2$ & $28 \cdot 5,41 \cdot 8$ & $<0.001$ \\
\hline Middle & 368 & $34 \cdot 5$ & $25 \cdot 8$ & $21 \cdot 3,30 \cdot 3$ & & $29 \cdot 1$ & $24 \cdot 4,33 \cdot 7$ & \\
\hline High to middle & 284 & $26 \cdot 6$ & $24 \cdot 3$ & $19 \cdot 3,29 \cdot 3$ & & $28 \cdot 5$ & $23 \cdot 3,33 \cdot 8$ & \\
\hline High & 214 & $20 \cdot 0$ & $16 \cdot 8$ & $11 \cdot 8,21 \cdot 9$ & & $19 \cdot 6$ & $14 \cdot 3,25 \cdot 0$ & \\
\hline BMl & 1077 & & & & & & & \\
\hline Normal & 447 & $41 \cdot 4$ & $5 \cdot 4$ & $3 \cdot 3,7 \cdot 5$ & $<0.001$ & $5 \cdot 6$ & $3 \cdot 5,7 \cdot 7$ & $<0.001$ \\
\hline Overweight & 421 & $39 \cdot 1$ & $28 \cdot 3$ & $23 \cdot 9,32 \cdot 6$ & & $35 \cdot 2$ & $30 \cdot 6,39 \cdot 7$ & \\
\hline Obese & 209 & $19 \cdot 4$ & $60 \cdot 3$ & $53 \cdot 6,67 \cdot 0$ & & $64 \cdot 1$ & $57 \cdot 6,70 \cdot 7$ & \\
\hline Physical activity & 1066 & & & & & & & \\
\hline Inactive & 192 & $18 \cdot 0$ & $26 \cdot 0$ & $19 \cdot 8,32 \cdot 3$ & 0.025 & $28 \cdot 1$ & $21 \cdot 7,34 \cdot 5$ & $0 \cdot 193$ \\
\hline Moderately inactive & 176 & $16 \cdot 5$ & $31 \cdot 3$ & $24 \cdot 3,38 \cdot 1$ & & $30 \cdot 7$ & $23 \cdot 8,37 \cdot 6$ & \\
\hline Moderately active & 543 & $51 \cdot 0$ & $24 \cdot 7$ & $21 \cdot 0,28 \cdot 3$ & & $29 \cdot 8$ & $26 \cdot 0,33 \cdot 7$ & \\
\hline Very active $\&$ active & 155 & $14 \cdot 5$ & $16 \cdot 1$ & $10 \cdot 3,22 \cdot 0$ & & $19 \cdot 4$ & $13 \cdot 1,25 \cdot 6$ & \\
\hline Smoking status & 1091 & & & & & & & \\
\hline Current (daily) & 318 & $29 \cdot 2$ & $19 \cdot 5$ & $15 \cdot 1,23 \cdot 9$ & 0.012 & $21 \cdot 4$ & $16 \cdot 9,25 \cdot 9$ & $<0.001$ \\
\hline Current (occasional) & 30 & $2 \cdot 8$ & $13 \cdot 3$ & $0 \cdot 4,26 \cdot 2$ & & $13 \cdot 3$ & $0 \cdot 4,26 \cdot 2$ & \\
\hline Past & 165 & $15 \cdot 1$ & $31 \cdot 5$ & $24 \cdot 4,38 \cdot 7$ & & $35 \cdot 8$ & $28 \cdot 4,43 \cdot 1$ & \\
\hline Never & 578 & $29 \cdot 1$ & $26 \cdot 5$ & $22 \cdot 9,30 \cdot 1$ & & $31 \cdot 3$ & $27 \cdot 5,35 \cdot 1$ & \\
\hline
\end{tabular}

MetS, metabolic syndrome; ATP III, National Cholesterol Education Program Adult Treatment Panel III; IDF, International Diabetes Foundation; N/A, not applicable.

*Row percentage.

+Widowed or divorced.

fNormal weight, $\mathrm{BMI}=18 \cdot 5-24 \cdot 9 \mathrm{~kg} / \mathrm{m}^{2}$; overweight, $\mathrm{BMI}=25 \cdot 0-29 \cdot 9 \mathrm{~kg} / \mathrm{m}^{2} ;$ obese, $\mathrm{BMI} \geq 30 \cdot 0 \mathrm{~kg} / \mathrm{m}^{2}$.

\section{Discussion}

To the best of our knowledge, this is the first cross-sectional study to describe the sociodemographic risk factors that are related to MetS in a representative sample from a Mediterranean adult population, applying two commonly used criteria to define MetS (from the ATP III panel and IDF). The results show that MetS was independently associated with age, sex, BMI, physical activity and social class. MetS was defined by both ATP III and IDF criteria because the two definitions gave reasonably different estimates of the global prevalence of MetS in this population $^{(11)}$. The IDF definition predicted a higher prevalence of MetS (classifying an additional group of individuals with MetS), which could have altered the risk factors associated with MetS between the two definitions. However, the results showed that the two definitions predicted similar risk factors for MetS, although the relationships between sex and physical activity and MetS were weaker when applying the IDF criteria.

As expected, age was an independent risk factor of MetS, which is a consistent finding in large studies ${ }^{(10,15)}$. Previous research on MetS in this population found that the prevalence of each of the components of MetS increased with age ${ }^{(11)}$. A number of explanatory diet- and lifestyle-related risk factors are likely to be involved, affecting weight and multiple metabolic abnormalities and explaining the life course development of MetS.

The protective effect of female gender on risk of MetS found in our study has also been reported in a study of a 
Table 3 Odds ratios of MetS according to sociodemographic risk factors, applying ATP III and IDF criteria: sub-sample of individuals aged 18-74 years from the 2002-2003 Health Survey of Catalonia

\begin{tabular}{|c|c|c|c|c|c|c|}
\hline \multirow[b]{2}{*}{ Demographic risk factor } & \multicolumn{3}{|c|}{ MetS, ATP III criteria } & \multicolumn{3}{|c|}{ MetS, IDF criteria } \\
\hline & OR & $95 \% \mathrm{Cl}$ & $P$ for trend & OR & $95 \% \mathrm{Cl}$ & $P$ for trend \\
\hline \multicolumn{7}{|l|}{ Age (years) } \\
\hline $18-34$ & $1 \cdot 0$ & referent & & $1 \cdot 0$ & referent & \\
\hline $35-44$ & $2 \cdot 1$ & $1 \cdot 1,4 \cdot 2$ & & $2 \cdot 5$ & $1 \cdot 3,4 \cdot 8$ & \\
\hline $45-54$ & $5 \cdot 2$ & $2 \cdot 7,9 \cdot 9$ & & $4 \cdot 4$ & $2 \cdot 4,8 \cdot 1$ & \\
\hline $55-64$ & $7 \cdot 1$ & $3 \cdot 7,13 \cdot 6$ & & $6 \cdot 0$ & $3 \cdot 2,11 \cdot 1$ & \\
\hline $65-74$ & $11 \cdot 1$ & $5 \cdot 6,22 \cdot 1$ & $<0.001$ & $12 \cdot 9$ & $6 \cdot 6,25 \cdot 1$ & $<0.001$ \\
\hline \multicolumn{7}{|l|}{ Sex } \\
\hline Male & $1 \cdot 0$ & referent & & $1 \cdot 0$ & referent & \\
\hline Female & 0.6 & $0.4,0.9$ & 0.010 & $0 \cdot 7$ & $0 \cdot 5,1 \cdot 0$ & 0.084 \\
\hline \multicolumn{7}{|l|}{$\mathrm{BMI}^{*}$} \\
\hline Normal & $1 \cdot 0$ & referent & & $1 \cdot 0$ & referent & \\
\hline Overweight & $4 \cdot 3$ & $2 \cdot 6,7 \cdot 0$ & & $6 \cdot 4$ & $3 \cdot 9,10 \cdot 5$ & \\
\hline Obese & $16 \cdot 4$ & $9 \cdot 6,28 \cdot 1$ & $<0.001$ & $22 \cdot 0$ & $12 \cdot 7,38 \cdot 1$ & $<0.001$ \\
\hline \multicolumn{7}{|l|}{ Physical activity } \\
\hline Inactive & $1 \cdot 0$ & referent & & $1 \cdot 0$ & referent & \\
\hline Moderately inactive & $1 \cdot 3$ & $0 \cdot 7,2 \cdot 4$ & & $1 \cdot 0$ & $0 \cdot 5,1 \cdot 8$ & \\
\hline Moderately active & $1 \cdot 1$ & $0 \cdot 7,1 \cdot 7$ & & $1 \cdot 2$ & $0.8,1 \cdot 9$ & \\
\hline Very active $\&$ active & 0.5 & $0.2,0.9$ & 0.054 & 0.5 & $0 \cdot 3,1 \cdot 0$ & $0 \cdot 361$ \\
\hline \multicolumn{7}{|l|}{ Social class } \\
\hline High & $2 \cdot 0$ & $1 \cdot 1,3 \cdot 7$ & 0.005 & $1 \cdot 9$ & $1 \cdot 1,3 \cdot 5$ & 0.013 \\
\hline High to middle & $1 \cdot 5$ & $0 \cdot 9,2 \cdot 6$ & & $1 \cdot 4$ & $0 \cdot 8,2 \cdot 4$ & \\
\hline Middle & $1 \cdot 1$ & $0 \cdot 6,1 \cdot 9$ & & $1 \cdot 1$ & $0 \cdot 7,1 \cdot 9$ & \\
\hline Low & $1 \cdot 0$ & referent & & $1 \cdot 0$ & referent & \\
\hline
\end{tabular}

MetS, metabolic syndrome; ATP III, National Cholesterol Education Program Adult Treatment Panel III; IDF, International Diabetes Foundation.

Models adjusted for age, sex, BMI, physical activity and social class.

${ }^{*}$ Normal weight, $\mathrm{BMI}=18 \cdot 5-24 \cdot 9 \mathrm{~kg} / \mathrm{m}^{2}$; overweight, $\mathrm{BMI}=25 \cdot 0-29 \cdot 9 \mathrm{~kg} / \mathrm{m}^{2}$; obese, $\mathrm{BMI} \geq 30 \cdot 0 \mathrm{~kg} / \mathrm{m}^{2}$.

Spanish working population ${ }^{(36)}$ and in other non-Mediterranean populations ${ }^{(14,37)}$. It is likely to be a reflection of the clinical finding that men experience CVD and related complications around 10 years earlier than women, whose risk increases more after menopause. It has long been hypothesised that the protective effect of oestrogen is involved, although the exact mechanisms behind this theory are still being investigated ${ }^{(38)}$.

Individuals were much more likely to have MetS if they were overweight or obese; nearly two-thirds of obese individuals had MetS, which is high and comparable to that observed in obese men in a US sample ${ }^{(12)}$. As abdominal obesity is a major determinant of MetS ${ }^{(39)}$, it is not surprising that being overweight/obese was a strong predictor of MetS prevalence in our study, which is consistent with previous research ${ }^{(12,14,40)}$. Nevertheless, BMI and abdominal obesity are not identical in terms of their pathophysiological role in MetS. When individuals with the same BMI and age but different body fat distributions are compared, those with central body fat have a greater risk of insulin resistance ${ }^{(41)}$. The specific role of abdominal obesity and visceral fat compared with gluteofemoral obesity in the aetiology of MetS has been attributed to differences in processes such as lipolysis, lipogenesis, fatty acid uptake, and secretion and expression of hormones and inflammatory factors ${ }^{(42)}$.

As in other Western societies, there are increasing trends in overweight/obesity in Catalonia (although obesity increased only in males and not females) ${ }^{(43)}$, which may be related in part to the documented deviation from the traditional $\mathrm{MDP}^{(33)}$. Moreover, there is also evidence that MetS prevalence is increasing in this region ${ }^{(11)}$. Whether greater adherence to the MDP within overweight/obese individuals in this population has a protective effect against MetS and related metabolic abnormalities remains to be investigated.

Higher levels of physical activity were independently associated with reduced risk of MetS, which is probably due to its effect on lipid profiles, insulin resistance, overweight/obesity status and other related risk factors ${ }^{(16)}$. The differences in the ATP III and IDF criteria resulted in $11 \cdot 1 \%$ of individuals being classified discordantly as with or without MetS ${ }^{(11)}$. This discrepancy may help explain why the protective effects of physical activity on MetS risk differed between the definitions (the effect was stronger and significant only when ATP III criteria were applied).

Social class was a strong independent risk factor for having MetS, which has been replicated in previous research on social class or related factors such as education level and household income ${ }^{(12,36)}$. For instance, a study of an active Spanish working population ${ }^{(36)}$ reported that manual labourers were significantly more likely to have MetS than managers and office workers. This increased risk is likely to be mediated through differences in dietary habits, such as adherence to the MDP, and other lifestyle characteristics between social classes, which could subsequently affect weight, lipid profiles, blood pressure and glucose levels.

The main limitation of the present study is its crosssectional design, which implies that the relationships 
between sociodemographic characteristics and MetS described should not be taken as causal. A further methodological issue is that the health survey was not specifically designed to explore the risk factors associated with MetS, and therefore some of the subgroups were very small, limiting the study's power to test for interactions. MetS was also defined without information on medication use for hypertriacylglycerolaemia which forms part of the ATP III and IDF definition (as the survey did not collect this information). However, this is unlikely to influence the results, as information on TAG levels was available and the population was probably unable to distinguish between medication use for triacylglycerolaemia and that for hypercholesterolaemia.

In conclusion, it is clear that there are important risk factors associated with having MetS in this Mediterranean population, as MetS was positively associated with age, male gender, BMI, physical inactivity and lower social status. Although these risk factors are similar to those found in non-Mediterranean populations, it is important to identify and assess them considering that MetS is high and becoming more prevalent in this population. In addition, Mediterranean populations are a distinctive study group because their traditional dietary pattern is protective against many cardiovascular risk factors that define MetS. Expanding our knowledge to give a better understanding of the relationship between sociodemographic risk factors for MetS should help when formulating public health strategies.

\section{Acknowledgements}

Authors have no conflict of interest. The study was funded, in part, by the Instituto de Salud Carlos III (Thematic Network G03/140 and RD06/0045, and PI051839), Spain. The authors wish to thank the Division of Public Health of the Autonomous Government of Catalonia and the Public Health Nutrition Research Centre of the University of Barcelona Science Park for facilitating access to the databases of the 2002-2003 Catalan Nutrition Survey; and the London School of Hygiene and Tropical Medicine, where G.B. followed an MSc in Public Health Nutrition and presented this work as a thesis under the supervision of Dr Sharon Cox, Dr Ricardo Uauy, J.S.-S. and L.S.-M. All authors have contributed in the design, analysis and/or writing of the manuscript. Specifically: G.B. and J.S.-S. had primary responsibility for manuscript preparation; G.B. was responsible for the statistical analysis; E.R. and L.S.-M. participated in the design of the ESCA study. All the authors contributed to the critical revision of the manuscript for important intellectual content.

\section{References}

1. Grundy SM, Cleeman JI, Daniels SR et al. (2005) Diagnosis and management of the metabolic syndrome: an American
Heart Association/National Heart, Lung, and Blood Institute Scientific Statement. Circulation 112, 2735-2752.

2. Nesto RW (2003) The relation of insulin resistance syndromes to risk of cardiovascular disease. Rev Cardiovasc Med 4, S11-S18.

3. Ford E (2004) The metabolic syndrome and mortality from cardiovascular disease and all-causes: findings from the National Health and Nutrition Examination Survey II Mortality Study. Atherosclerosis 173, 309-314.

4. Gami AS, Witt BJ, Howard DE, Erwin PJ, Gami LA, Somers VK \& Montori VM (2007) Metabolic syndrome and risk of incident cardiovascular events and death: a systematic review and meta-analysis of longitudinal studies. J Am Coll Cardiol 49, 403-414.

5. Ford ES, Giles WH \& Mokdad AH (2004) Increasing prevalence of the metabolic syndrome among US adults. Diabetes Care 27, 2444-2449.

6. Alvarez Leon EE, Ribas BL \& Serra Majem L (2003) Prevalence of metabolic syndrome in the population of the Canary Islands. Med Clin (BarC) 120, 172-174.

7. Athyros VG, Bouloukos VI, Pehlivanidis AN et al. (2005) The prevalence of the metabolic syndrome in Greece: The MetS-Greece Multicentre Study. Diabetes Obes Metab 7, 397-405.

8. Marquezine GF, Oliveira CM, Pereira AC, Krieger JE \& Mill JG (2007) Metabolic syndrome determinants in an urban population from Brazil: social class and genderspecific interaction. Int J Cardiol (Epublication ahead of print version).

9. Lorenzo C, Williams K, Gonzalez-Villalpando C \& Haffner SM (2005) The prevalence of the metabolic syndrome did not increase in Mexico City between 1990-1992 and 1997-1999 despite more central obesity. Diabetes Care 28, 2480-2485.

10. Kuzuya M, Ando F, Iguchi A \& Shimokata H (2006) Age-specific change of prevalence of metabolic syndrome: longitudinal observation of large Japanese cohort. Atherosclerosis 191, 305-312.

11. Buckland G, Salas-Salvadó J, Serra-Majem L \& Castells C (2007) Is metabolic syndrome increasing in the Mediterranean population? J Nutr (In the Press).

12. Park YW, Zhu S, Palaniappan L, Heshka S, Carnethon MR \& Heymsfield SB (2003) The metabolic syndrome: prevalence and associated risk factor findings in the US population from the Third National Health and Nutrition Examination Survey, 1988-1994. Arch Intern Med 163, 427-436.

13. Edwards K, Austin M, Newman B, Mayer E, Krauss R \& Selby J (1994) Multivariate analysis of the insulin resistance syndrome in women. Arterioscler Thromb 14, 1940-1945.

14. Hillier TA, Fagot-Campagna A, Eschwege E, Vol S, Cailleau M \& Balkau B; the DESIR Study Group (2006) Weight change and changes in the metabolic syndrome as the French population moves towards overweight: The DESIR cohort. Int J Epidemiol 35, 190-196.

15. Ford ES, Giles WH \& Dietz WH (2002) Prevalence of the metabolic syndrome among US adults: findings from the Third National Health and Nutrition Examination Survey. JAMA 287, 356-359.

16. Brouwer B, Visseren F, van der Graaf Y \& Group SS (2007) The effect of leisure-time physical activity on the presence of metabolic syndrome in patients with manifest arterial disease. The SMART study. Am Heart $J$ 154, $1146-1152$.

17. Masulli M, Riccardi G, Galasso R \& Vaccaro O (2006) Relationship between smoking habits and the features of the metabolic syndrome in a non-diabetic population. Nutr Metab Cardiovasc Dis 16, 364-370.

18. Trichopoulou A (2004) Traditional Mediterranean diet and longevity in the elderly: a review. Public Health Nutr 7, 943-947. 
19. Tunstall-Pedoe H, Kuulasmaa K, Mahonen M, Tolonen H, Ruokokoski E \& Amouyel P (1999) Contribution of trends in survival and coronary-event rates to changes in coronary heart disease mortality: 10-year results from 37 WHO MONICA project populations. Monitoring trends and determinants in cardiovascular disease. Lancet $\mathbf{3 5 3}$, $1547-1557$.

20. Keys A, Karvonen M, Menotti A et al. (1986) The diet and 15-year death rate in the seven countries study. Am J Epidemiol 124, 903-915.

21. Muzio F, Mondazzi L, Harris WS, Sommariva D \& Branchi A (2007) Effects of moderate variations in the macronutrient content of the diet on cardiovascular disease risk factors in obese patients with the metabolic syndrome. Am J Clin Nutr 86, 946-951.

22. Panagiotakos DB, Pitsavos C, Arvaniti F \& Stefanadis C (2007) Adherence to the Mediterranean food pattern predicts the prevalence of hypertension, hypercholesterolemia, diabetes and obesity, among healthy adults; the accuracy of the MedDietScore. Prev Med 44, 335-340.

23. Tortosa A, Bes-Rastrollo M, Sanchez-Villegas A, BasterraGortari FJ, Nunez-Cordoba JM \& Martinez-Gonzalez MA (2007) Mediterranean diet inversely associated with the incidence of metabolic syndrome: the SUN prospective cohort. Diabetes Care 30, 2957-2959.

24. Estruch R, Martínez-González M, Corella D et al. (2006) Effect of a Mediterranean-style diet on cardiovascular risk factors. Ann Intern Med 145, 1-11.

25. Panagiotakos DB \& Polychronopoulos E (2005) The role of Mediterranean diet in the epidemiology of metabolic syndrome; converting epidemiology to clinical practice. Lipids Health Dis $\mathbf{4}, 7$.

26. Tzima N, Pitsavos C, Panagiotakos DB, Skoumas J, Zampelas A, Chrysohoou C \& Stefanadis C (2007) Mediterranean diet and insulin sensitivity, lipid profile and blood pressure levels, in overweight and obese people; the Attica study. Lipids Health Dis 6, 22.

27. Fitó M, Guxens M, Corella D et al. (2007) Effect of a traditional Mediterranean diet on lipoprotein oxidation: a randomized controlled trial. Arch Intern Med 167, 1195-1203.

28. Meydani M (2005) A Mediterranean-style diet and metabolic syndrome. Nutr Rev 63, 312-314.

29. Esposito K, Marfella R, Ciotola M, Di Palo C, Giugliano F, Giugliano G, D'Armiento M, D'Andrea F \& Giugliano D (2004) Effect of a Mediterranean-style diet on endothelial dysfunction and markers of vascular inflammation in the metabolic syndrome: a randomized trial. JAMA 292, $1440-1446$.

30. Ruidavets JB, Bongard V, Dallongeville J, Arveiler D, Ducimetière P, Perret B, Simon C, Amouyel P \& Ferrières J (2007) High consumptions of grain, fish, dairy products and combinations of these are associated with a low prevalence of metabolic syndrome. J Epidemiol Community Health 61, 810-817.

31. Alvarez Leon EE, Henriquez P \& Serra-Majem L (2006) Mediterranean diet and metabolic syndrome: a crosssectional study in the Canary Islands. Public Health Nutr 9, 1089-1098.

32. Generalitat de Catalunya (2000) Avaluació dels objectius per a l'any 2000 del Pla de Salut de Catalunya. Barcelona: Generalitat de Catalunya, Departament de Sanitat i Seguretat Social.

33. Serra Majem L, Ribas-Barba L, Salvador G, Castells C, Salleras L \& Plasencia A (2007) Trends in dietary habits and food consumption in Catalonia, Spain (1992-2003). Public Health Nutr 10, 1340-1353.

34. The International Diabetes Federation (2005) New worldwide definition of the metabolic syndrome. http://www. idf.org/webdata/docs/IDF_Metasyndrome_definition.pdf

35. World Health Organization (2000) Obesity: Preventing and Managing the Global Epidemic. Report of a WHO Consultation on Obesity. Technical Report Series no. 894. Geneva: WHO.

36. Alegria E, Cordero A, Laclaustra M, Grima A, León M, Casasnovas JA, Luengo E, del Río A \& Ferreira I; Investigadores del registro MESYAS (2005) Prevalence of metabolic syndrome in the Spanish working population: MESYAS registry. Rev Esp Cardiol 58, 797-806.

37. Balkau B (2005) Epidemiology of the metabolic syndrome and the RISC study. Eur Heart J Suppl 7, Suppl. D, D6-D9.

38. Ng MK (2007) New perspectives on Mars and Venus: unravelling the role of androgens in gender differences in cardiovascular biology and disease. Heart Lung Circ 16, 185-192.

39. Carr DB, Utzschneider KM, Hull RL, Kodama K, Retzlaff BM, Brunzell JD, Shofer JB, Fish BE, Knopp RH \& Kahn SE (2004) Intra-abdominal fat is a major determinant of the National Cholesterol Education Program Adult Treatment Panel III criteria for the metabolic syndrome. Diabetes $\mathbf{5 3}$, 2087-2094.

40. Noale M, Maggi S, Marzari C, Limongi F, Gallina P, Bianchi D \& Crepaldi G; ILSA Working Group (2006) Components of the metabolic syndrome and incidence of diabetes in elderly Italians: The Italian Longitudinal Study on Aging. Atherosclerosis 187, 385-392.

41. Raji A, Seely EW, Arky RA \& Simonson DC (2001) Body fat distribution and insulin resistance in healthy Asian Indians and Caucasians. J Clin Endocrinol Metab 86, 5366-5371.

42. Hansen E, Hajri T \& Abumrad NN (2006) Is all fat the same? The role of fat in the pathogenesis of the metabolic syndrome and type 2 diabetes mellitus. Surgery 139, 711-716.

43. Serra J, Castell C, Serra L, Taberner J \& Salleras L (2003) [Overweight and obesity. Evaluation of the objectives of the Health Plan for Catalonia for the year 2000]. Med Clin (Barc) 121, Suppl. 1, 47-50. 